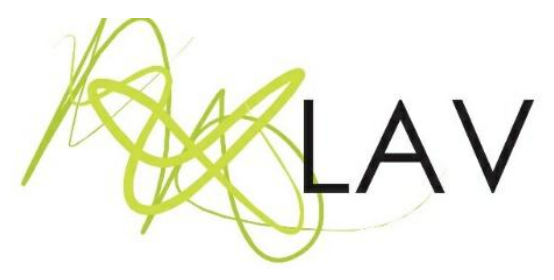

\title{
Pensando a educação infantil a partir de imagens
}

Thinking child education from images

\author{
Nara Mendes Moreira \\ Universidade Federal de Goiás \\ Carla Luzia de Abreuii \\ Universidade Federal de Goiás
}

\section{Resumo}

O presente artigo focaliza o uso de imagens na Educação Infantil da Rede Municipal de Educação de Goiânia. Esse exercício de escrita se preocupa em questionar sobre como as crianças constroem imagens, além de pensar em como as professoras e professores dessa etapa da Educação Básica vem utilizando as imagens como recursos metodológicos. Para isso, desenvolvemos um breve estudo acerca da concepção de criança apresentada no documento curricular de Goiânia para a Educação Infantil. Também realizamos uma pesquisa bibliográfica fundamentada nos estudos de Cunha (2007), Martins (2010) e Derdyk (2015) que abordam o uso de imagens na educação da primeira infância e as formas de se pensar o desenho na Educação Infantil. Dessa forma, evidenciamos o modo como as imagens contribuem para a construção de imaginários e discutimos sua importância e potencialidade nos processos de ensino do público infantil.

Palavras-chave: educação infantil, imagens, visualidades, currículo.

\begin{abstract}
This article focuses on the use of images in Early Childhood Education in the Municipal Education Network in Goiânia, Brazil. This writing exercise is concerned with questioning how children build images, in addition to thinking about how teachers in this stage of Basic Education have been using images as methodological resources. For this, we developed a brief study about the conception of child presented in the curriculum document of Goiânia for Early Childhood Education. We also conducted a bibliographic research based on the studies of Cunha (2007), Martins (2010) and Derdyk (2015) that address the use of images in early childhood education and the ways of thinking about drawing in early childhood education. Thus, we highlight the way in which images contribute to the construction of imaginaries and discuss their importance and potential in the teaching processes for children.
\end{abstract}

Keywords: child education, images, visualities, curriculum. 


\title{
A criança na Educação Infantil de Goiânia
}

Antes de abordar os aspectos das imagens construídas por crianças, é preciso compreender qual concepção de criança adotamos neste artigo. Partimos do contexto político e pedagógico da Educação Infantil na Rede Municipal de Educação (RME) de Goiânia, apresentado na Proposta Político-Pedagógica Infâncias e Crianças em Cena: por uma Política de Educação Infantil para a Rede Municipal de Educação de Goiânia (2014), que firma a concepção de criança e infância dentro do campo de estudos da Pedagogia da Infância, compreendendo a criança como um ser social, histórico e de direitos.

\begin{abstract}
Nesse sentido, a Pedagogia da Infância apresenta como base epistemológica a Teoria Histórico-Cultural reconhecendo a necessidade de articulação de diferentes campos teóricos Sociologia, Antropologia, Psicologia, Educação e História - para compreender o sujeito criança (GOIÂNIA, 2014, p. 12).
\end{abstract}

A Pedagogia da Infância "valoriza a cultura da criança, bem como suas dimensões intelectuais, criativas, estéticas, expressivas e emocionais" (GOIÂNIA, 2014, p. 13), percebendo-a como ser atuante do mundo em que vive, capaz de ressignificar e produzir conhecimentos por meio de trocas e interações com o ambiente e com o outro.

Ao considerar seu postulado na Pedagogia da Infância, a Educação Infantil na RME apresenta um currículo flexível, em que as aprendizagens e o desenvolvimento das crianças são organizados em cada instituição, a partir de planejamentos intencionais, sistemáticos e com objetivos nítidos. Essa organização é definida coletivamente no Projeto Político Pedagógico pelos profissionais das instituições, onde é desdobrado ao longo do ano em projetos de trabalho, planejamentos e em variadas situações de aprendizagem.

A organização do trabalho pedagógico na RME viabiliza às professoras e aos professores uma maior sensibilidade pelos interesses das crianças, já que de acordo com a Proposta Político Pedagógica, as aprendizagens precisam ser concebidas, pensadas e planejadas com base no contexto e no interesse do grupo envolvido na construção de conhecimentos. Essa Proposta compreende que o processo de constituição de aprendizagens, desenvolvimento e subjetividade se dá por meio das relações entre o indivíduo, a sociedade e o meio, como pontuado a seguir:

Os indivíduos se constituem na sua relação com a natureza, com outros indivíduos, por meio da atividade, a partir de condições históricas concretas. Logo, os indivíduos dependem da relação com outros indivíduos para se constituírem. Dessa feita, compreendemos que as crianças aprendem e se desenvolvem nas interações e práticas cotidianas a elas disponibilizadas e por elas

Revista Digital do LAV - Santa Maria - vol. 14, n. 1, p. 89 - 102 - jan./abr. 2021 ISSN 1983 - 7348 
estabelecidas, com adultos, jovens e pares de diferentes grupos e contextos culturais (GOIÂNIA, 2014, p. 30).

A Educação Infantil em Goiânia se formula nos princípios de uma educação para a cidadania em que a criança é vista como produtora de cultura, resultante de interações de um movimento de troca em que é capaz de produzir significados, elaborar e interpretar sentidos para sua existência. É possível entender, assim, que a criança na Educação Infantil da RME de Goiânia é compreendida a partir de seu percurso social e histórico, pautado em uma concepção de infância que valoriza os modos de pensar, agir, expressar-se e se ver no mundo.

\section{O uso de diferentes linguagens na Educação Infantil}

O ambiente escolar é sempre repleto de imagens. Muitas delas têm o objetivo de decorar o ambiente, chamar a atenção da criança e de ser um recurso metodológico. $\mathrm{Na}$ Educação Infantil, as imagens estão ainda mais presentes, porque todos os espaços das instituições que atendem crianças pequenas precisam ser, de alguma forma, espaços 'educadores'1 ${ }^{1}$ para promover aprendizagens.

Na Proposta Político Pedagógica da Educação Infantil de Goiânia, existe uma preocupação acerca da identidade do espaço físico das instituições. O documento, inclusive, aponta para a importância de perceber "as concepções e práticas que dali emergem: os cartazes, as pinturas e as produções são estereotipadas apresentando uma visão adultocêntrica? Ou revelam a atuação da criança?" (GOIÂNIA, 2014, p. 133). Essa preocupação se dá pelo fato de ser recorrente em instituições escolares a exposição e a exploração de imagens produzidas por adultos, como afirma a pesquisadora Alice Martins:

Uma das marcas dessas visualidades é que, em sua maioria, são produzidas por adultos cuja intenção é reproduzir traçados supostamente relacionados a um certo gosto infantil... Nesse trabalho, adultos empenham-se em copiar modelos, tentando reproduzir figuras, personagens, ambientes gráficos veiculados por meios de comunicação, livros didáticos, indústria do entretenimento, ou mesmo reunidos em arquivos escolares, disponíveis para esse fim. Alguns professores e funcionários aperfeiçoam-se nos processos de fazer cópias e reproduções. Muitos orgulham-se disso. É importante ressaltar que, raramente,

\footnotetext{
${ }^{1}$ Neste artigo compreendemos por espaços educadores todo o ambiente escolar que por meio de organização física e estética comunica mensagens, instrui e educa crianças. Na Educação Infantil, esses espaços são importantes, pois eles podem contemplar diversas linguagens e, quando bem pensados por profissionais da educação e organizados em conjunto com as crianças, são capazes de suscitar questionamentos, provocar a imaginação, a criatividade e refletir identidades.
} 
desenhos de criança fazem parte desses repertórios imagéticos (MARTINS, 2010, p. 10).

Nossas experiências e trânsitos pelas instituições de ensino da cidade apontam que, em geral, o uso de imagens com uma visão adultocêntrica no ambiente escolar é o cenário encontrado em muitas instituições de Educação Infantil, apesar das orientações dos documentos norteadores, tanto em âmbito municipal quanto nacional. Esses documentos ressaltam a importância de valorizar e expressar a identidade das crianças no ambiente escolar em que estão inseridas.

Em Goiânia, a discussão sobre o currículo na Educação Municipal evidencia a importância de garantir que as crianças aprendam e se desenvolvam por meio de interações, expressando assim seus processos, sua criatividade e sua identidade, a fim de que se firmem como sujeitos inseridos dentro de seus grupos sociais.

Nas Diretrizes Curriculares Nacionais para a Educação Infantil de 2010, o Ministério da Educação (MEC) propõe que o currículo para essa etapa do Ensino Básico não seja prescritivo, delimitando conteúdos. Assim, é preciso considerar um currículo em construção que emerge da vida, dos encontros entre os sujeitos e a cultura, além de valorizar as vivências e interesses das crianças com o intuito de ampliar, diversificar e complexificar conhecimentos com a mediação dos profissionais da educação.

Pensando na criança como ser singular, mas com capacidades plurais, a Proposta Político Pedagógica da RME de Goiânia destaca as possibilidades de manifestação das crianças por meio de diferentes expressões pautadas principalmente nas práticas sociais. De acordo com o documento que rege a Educação Infantil em Goiânia, as linguagens são práticas sociais significativas na aprendizagem e no desenvolvimento da criança, pois a compreensão de mundo acontece por meio da expressão de linguagens. É importante frisar que as linguagens são capazes de subsidiar ações e conhecimentos na Educação Infantil por meio de seus sistemas simbólicos. Dessa maneira, o documento propõe que

[o] trabalho pedagógico na Educação Infantil precisa prever o tempo de criação, valorizando, assim, o ato criador e a construção pelas crianças de respostas singulares por meio de significativas experiências e vivências, as quais ampliarão as possibilidades de expressar, comunicar e criar, de organizar pensamentos e ideias, de conviver, brincar e trabalhar em grupo, de ter iniciativa e buscar soluções para os problemas e conflitos que apresentam às mais diferentes idades, possibilitarão também a apropriação de diferentes linguagens e saberes que circulam em nossa sociedade (GOIÂNIA, 2014, p. 78). 
O mesmo documento destaca ainda a necessidade do trabalho com as diferentes linguagens, dentre elas a Linguagem Oral, a Linguagem Escrita, a Linguagem Corporal, as Linguagens Artísticas e a Linguagem Musical. É necessário ainda ressaltar a impossibilidade de trabalho com apenas uma determinada linguagem, já que elas dialogam entre si e a ação pedagógica pressupõe um trabalho interdisciplinar capaz de atender às múltiplas capacidades de expressão das crianças.

Dentro das Linguagens Artísticas, o desenho é um dos mais utilizados como forma de expressão das crianças. No entanto, essa modalidade requer uma compreensão para além do desenvolvimento de habilidades artísticas, de imaginação ou de criatividade. É importante que seja entendido, também, como uma forma de relação com o mundo, como defende a artista e pesquisadora Edith Derdyk:

O desenho requisita uma postura global. Desenhar não é copiar formas, figuras, não é simplesmente proporção, escala. A visão parcial de um objeto revelará um conhecimento parcial desse mesmo objeto. Desenhar objetos, pessoas, situações, animais, emoções, ideias são tentativas de aproximação com o mundo. Desenhar é conhecer, é apropriar-se (DERDYK, 2015, p. 38).

Em convergência com Derdyk (2015), a pesquisadora Alice Martins (2010) faz uma significativa consideração sobre a construção da autoimagem pela criança. Para ela, desde cedo, a criança constrói sua autoimagem por meio das percepções e relações que estabelece com o meio e com os outros indivíduos. Essas relações que estão em constante construção resultam em vivências que são capazes de tecer conhecimentos.

Dessa forma, a imagem que cada pessoa elabora sobre si, de modo sempre dinâmico, resulta da sua história de vivências desde o próprio corpo, que é o espaço que cada um ocupa no universo, na relação com os demais e o meio em que vive, o que envolve conquistas, tensões, frustrações, desejos, ambiguidades, dúvidas... Se cada corpo é único e tem uma história igualmente única, se cada pessoa manifesta-se no mundo com o seu corpo e sua história, ao mesmo tempo, cada corpo conta uma história que também é social, coletiva, cultural, histórica. Assim, além de suas construções individuais e únicas, a cada um cabe participar da caminhada que a humanidade cumpre, produzindo conhecimento, fazeres, símbolos, modos de vida, visões de mundo, formas de expressão coletivas (MARTINS, 2010, p. 2).

Portanto, o trabalho com o desenho na Educação Infantil se mostra como um importante meio para a expressão das crianças, ajudando-as a se tornarem indivíduos críticos, sensíveis e pertencentes ao contexto em que vivem. Para isso, é importante que os profissionais de educação compreendam a amplitude do trabalho em intersecção com as diferentes linguagens, considerando as diferentes possibilidades de manifestações, 
dentre elas, o desenho, como forma de expressão, experimentação e elaboração de si e do mundo.

\section{A criança e o desenho}

O desenho pode ser compreendido como um sistema de representação capaz de desenvolver conhecimento por meio da comunicação e da expressão. Muitas vezes, o desenho consegue extrapolar o que está no papel já que ele tem a capacidade de nos fazer enxergar, imaginar e buscar interpretações para aquilo que está representado. Como pontua Etiene Samain,

[...] toda imagem (um desenho, uma pintura, uma escultura, uma fotografia, um fotograma de cinema, uma imagem eletrônica ou infográfica) nos oferece algo para pensar: ora um pedaço de real para roer, ora uma faísca de imaginário para sonhar (SAMAIN, 2014, p. 22).

O olhar aventureiro da criança que busca novas descobertas e constrói narrativas fantásticas faz parte de seu estado em contínuo movimento. A criança "vive em estado de encantamento diante dos objetos, das pessoas e das situações que a rodeiam" (DERDYK, 2015, p. 24). O ato de desenhar possibilita que a criança vá além do que está posto, desenvolvendo outras manifestações de sentido, o que promove a ampliação de seu potencial imaginativo.

Quando a criança desenha, ela também está colocando no papel o resultado de suas vivências e interações. As propostas curriculares para a Educação Infantil preveem que às crianças, desde muito pequenas, seja-Ihes assegurado tempo de criação por meio de experiências significativas que possibilitem expressão e comunicação. De acordo com Martins,

[...] toda criança cresce enquanto brinca com outras crianças, com os objetos, enquanto experimenta seu corpo, pesquisa o tempo, o espaço e as relações no meio sócio cultural em que se encontra; enquanto se expressa através do gesto, do traço, da cor, do grito, do riso, do jogo, do canto, do sonho e da fantasia. Toda criança é lúdica em seu desejo por saber, descobrir, construir... Toda criança é lúdica enquanto aprende a complexa teia de códigos, signos, significados dos caminhos que deve trilhar para tornar-se sujeito social, para estabelecer vínculos de pertencimento, identidades (MARTINS, 2010, p. 1).

As vivências e as experiências das crianças com o outro e o meio dão origem a repertórios imagéticos que podem ser compreendidos como visualidades. A autora Gillian 
Rose (2001) propõe uma interessante diferenciação entre visão e visualidade. Para ela, a primeira está relacionada à fisiologia dos olhos, ao ato de ver, enquanto a segunda pode ser compreendida como a maneira com a qual aprendemos a interpretar e compreender o mundo a partir das imagens. A visualidade, então, está relacionada diretamente às nossas vivências e ao nosso modo de ver que é construído culturalmente.

Quando a criança desenha a si mesma no papel, ela não está apenas expondo o seu esquema corporal, mas também sua autoimagem de acordo com sua percepção de mundo. Martins (2010) propõe que, ao desenhar, a criança apresenta dados sobre o seu meio sociocultural, elaborando e articulando informações cognitivas e afetivas. Assim, o desenho não é só expressão gráfica, ele diz respeito às manifestações da criança e à sua necessidade de desenvolvimento. O desejo de representação é projetado pela criança em seus riscos, rabiscos e garatujas que refletem seu desenvolvimento mental, psíquico e emocional.

Para muitos adultos, as primeiras manifestações gráficas da criança são compreendidas como rabiscos sem sentido - traços que, muitas vezes, até perpassam os limites do papel. Porém, esses rabiscos podem ser entendidos como manifestações do corpo, gestos que por ora ainda não têm o compromisso de comunicar, mas que gradativamente vão ganhando significados de representações sociais.

Aos poucos, os rabiscos se modificam, incorporando intencionalidades, sentidos, ampliando, portanto, as possibilidades representacionais. A criança descobre a possibilidade de produzir marcas, registros que podem significar coisas, evocar fatos, pessoas e objetos, e mais, podem ser decodificados por outras pessoas (MARTINS, 2010, p. 4).

A intencionalidade das garatujas produzidas pelas crianças está intimamente ligada ao domínio corporal. Os rabiscos, muitas vezes, indecifráveis para nós adultos, são resultados de uma ação corporal da criança, como argumenta Edith Derdyk (2015). Essa ação que se concentra na ponta do lápis, elo de ligação entre o corpo e o papel, passeia pela folha e é capaz de captar todo o estímulo do sistema motor, nervoso e psíquico.

As experiências sensório-motoras proporcionadas às crianças desde cedo promovem as habilidades de visualizar, relacionar e simbolizar significados para os traços expressos no papel. São nessas experiências de expressão do corpo e dos movimentos gestuais no papel que a criança descobre a possibilidade de registrar e compreender que seu desenho pode ter significado não só para ela, mas também para outras pessoas. Sobre isso, Martins evidencia que 
[...] ao possibilitar a vivência de questões como essas, o exercício do desenhar entrecruza a expressão individual da criança com as construções de sentido no contexto da cultura. Assim considerado, o ato de desenhar é individual e coletivo, tem marcas espontâneas de experimentação, e ao mesmo tempo observa conjuntos normativos do viver em sociedade (MARTINS, 2010, p. 4).

Desenhar é, então, uma prática que auxilia a criança a conhecer e se estabelecer em seu contexto. Ao desenhar a criança está expressando aquilo que entende do mundo e se tornando presente nele.

\section{A construção de imagens na Educação Infantil}

Diferente do adulto, a criança tem um olhar sensível e consegue perceber o mundo de maneira original e distinta. Para ela, um risco no papel pode se transformar em uma pessoa, em um animal ou em um objeto.

De acordo com a professora e pesquisadora Susana Rangel Vieira da Cunha (2007), as crianças, assim como os artistas, percebem o mundo de maneira "mais aguçada do que a maioria dos adultos que deixam para trás essa capacidade humana de ver, imaginar e simbolizar" (CUNHA, 2007, p. 4).

Ainda na infância, muitas crianças entram em um condicionamento cultural produzido e ofertado por adultos, deixando sua capacidade de abstração limitada. Isso se deve a diversos fatores que ajudam a criança a construir seu repertório imagético inserido em cenários visuais específicos. Dentre eles, estão as imagens disseminadas pelos meios de comunicação e de entretenimento que oferecem interpretações sobre o mundo e são capazes de moldar as visualidades das crianças, consequentemente, esses repertórios imagéticos. Sobre a infinidade de imagens disponibilizadas às crianças, Derdyk expõe:

A criança, hoje em dia, convive com um repertório inimaginável para qualquer criança e adulto do século passado. Antes de a criança ver e reconhecer o Sol, a luz, as estrelas e o céu, imagine só, ela já viu suas representações em algum livro ou tela. Vivemos hoje sob o signo da ficção e da paródia (DERDYK, 2015 p. 59).

Além das visualidades difundidas pela cultura visual contemporânea, que muitas vezes direcionam as maneiras de ver e de pensar as imagens, a escola também contribui para a subordinação do olhar da criança e de seu potencial criativo. Pesquisas que envolvem o universo infantil apontam o empobrecimento gradual da expressão gráfica ao longo da vida escolar. O trabalho massivo com a coordenação motora fina, o uso de 
cópias e o destaque ao desenvolvimento do traçado de letras e números fazem com que o processo de desenvolvimento gráfico infantil seja inibido.

Dessa forma,

[...] a escola é o agente transmissor cultural. A necessidade de organizar o conhecimento, para poder comunicá-lo, muitas vezes torna o próprio conhecimento compartimentado, classificatório e redutor. A escola, porta-voz de uma visão do mundo, pode subliminarmente aprisionar a capacidade de a criança perceber e compreender o mundo por si mesma: este lhe é dado, apresentado e assinado (DERDYK, 2015, p. 108).

Embora haja exceções, ainda é comum no sistema de ensino o uso de cópias ou o direcionamento do desenho. Esses tipos de atividades não correspondem àquilo que é proposto pelos documentos norteadores da Educação Infantil que, como já foi abordado no texto, preveem um ensino pautado nos interesses das crianças e em sua capacidade de expressão. Ao fornecer um modelo de desenho a ser seguido, a escola não valoriza as necessidades da criança, tornando-se "um depósito de informação sem reflexão, exercício de poder e da dominação" (DERDYK, 2015, p. 108).

Compreendendo o caráter formativo que as imagens podem estabelecer com aspectos que constituem a identidade, Fernando Hernández (2013) revela que a escola ainda apresenta dificuldade em desenvolver trabalhos que proporcionem experiências emancipadoras no que tange às imagens. Para o autor, o trabalho com imagens deve ter como finalidade "explorar nossa relação com as práticas do olhar, as relações de poder em que somos colocados, e questionar as representações que construímos de nossas relações com os outros" (HERNÁNDEZ, 2013, p. 92). Ao encarar as imagens de maneira mais crítica e reflexiva, a escola colabora para romper com a função reprodutora de visualidades hegemônicas.

O conceito de visualidade conectada à autoridade e ao poder de dominação foi discutido por Nicholas Mirzoeff (2016) que aborda o direito a olhar não apenas como uma questão meramente relacionada à visão, mas sim ao contexto em que o indivíduo está inserido e a partir de onde emergem os discursos que orientam as práticas sociais. Para o autor, o direito a olhar está diretamente relacionado à autonomia e à subjetividade:

A autonomia reivindicada pelo direito a olhar tem sido, e continua a ser, oposta pela autoridade da visualidade. Apesar do nome, este processo não é composto apenas de percepções visuais no sentido físico, mas é formado por um conjunto de relações que combinam informação, imaginação e introspecção em uma interpretação do espaço físico e psíquico (MIRZOEFF, 2016, p. 748). 
Nessa direção, orientar a expressão da criança delimitando o que deve ser desenhado, onde deve ser traçado e como deve ser colorido, limita sua manifestação expressiva, anula as experiências que já carrega consigo e adestra o olhar da criança à autoridade do adulto, limitando, também, o seu direito de olhar o mundo com seus próprios olhos.

As crianças recebem diariamente uma enormidade de manifestações visuais vindas do ambiente em que vivem, a partir da televisão, dos computadores, dos gibis, das revistas e, para muitas, a partir de artefatos digitais que oferecem um universo de imagens e vídeos. Esses repertórios imagéticos também entram pelos muros das escolas e convivem, não sem conflitos, com o ambiente disciplinar e formativo.

Existe ainda no ambiente da Educação Infantil a recorrência em práticas que pedem a produção de cópias ou releituras de imagens de obras artísticas. Em geral, a expectativa de que a cópia da imagem representada corresponda exatamente ao modelo original que foi replicada é frustrada. O ato de desenhar não se limita ao ato de copiar. Quando a criança copia, está construindo uma representação estereotipada da realidade, levando em consideração apenas o que está evidente, reduzindo o significado de suas vivências e experiências que poderiam ser percebidas e elaboradas de maneira mais rica e significativa. Dessa forma,

[o] ensino fundamentado na cópia inibe toda e qualquer manifestação expressiva e original. A criança, autorizada a agir dessa forma, certamente repetirá fórmulas conhecidas diante de qualquer problema ou situação que exige respostas. Ela, com todo o seu potencial aventureiro, deixa de se arriscar, de se projetar. Seu desenho enfraquece, tal como seu próprio ser (DERDYK, 2015, p. 110).

É importante ressaltar que os educadores e as educadoras também se encontram vulneráveis ao que tange à autonomia de olhar e a como trabalhar com imagens. Isso porque grande parte dos materiais disponíveis como suporte pedagógico apresentam uma visão carregada de estereótipos em relação ao universo infantil. Para Martins,

[...] desenhos de crianças, em geral, diferem substancialmente das ilustrações de livros destinados ao público infantil, de livros didáticos, e também das coletâneas de desenhos pedagógicos que circulam nos ambientes escolares. Estas ilustrações são desenhos de adultos que visam o público infantil, com traço e estilos próprios (MARTINS, 2010, p. 13).

Além disso, na Educação Infantil existe uma carência na formação do corpo docente. São raros os profissionais atuantes formados na área de Artes Visuais em relação aos demais professores, em sua maioria pedagogas (os), que apresentam uma 
formação deficitária sobre as questões inerentes ao uso de imagens nas atividades pedagógicas.

Pensando na falta de intimidade que muitas professoras e professores estabelecem com as imagens construídas pelas crianças no ambiente escolar, existe uma preocupação nos documentos norteadores da Educação Infantil, tanto em âmbito nacional quanto municipal, sobre o uso de imagens como registro de aprendizagens das crianças. Essas notações favorecem o acompanhamento de pais e pessoas da família em relação aos percursos e vivências das crianças nas instituições.

Algumas pesquisas têm sido realizadas em todo o Brasil nesse sentido, dentre elas, a de Luciana Esmeralda Ostetto (2017), que tem contribuído com as experiências sobre a realização de registros de aprendizagens na Educação Infantil. A autora afirma que ao registrar o trabalho desenvolvido com e pelas crianças por meio de fotos, relatos, anotações, painéis, dentre outras formas, professoras e professores estão não somente construindo documentação, mas também pensando sobre sua prática, apropriando-se do seu percurso e ensaiando autoria. A autora afirma que

[...] para registrar, no cotidiano vivido com um grupo de crianças, é necessário observar ações, reações, interações, proposições não só das crianças, mas também do próprio docente. É preciso ficar atento às dinâmicas do grupo, às implicações das relações pedagógicas, com um olhar aberto e sensível, pois registrar não é uma técnica, nem tampouco pode ocorrer de forma automatizada, como a espelhar o real (OSTETTO, 2017, p. 27).

Nesse sentido, o registro na Educação Infantil é um instrumento que possibilita ao adulto a compreensão dos processos de desenvolvimento das crianças. Ao observar e registrar, é possível conhecer as potencialidades do grupo envolvido nos saberes e as possibilidades de trabalho com as formas de pensar das crianças.

As narrativas construídas em relatos e imagens nos registros de aprendizagem da Educação Infantil fazem parte da memória de experiências vividas no ambiente escolar, que, por vezes, silenciam adultos e crianças com seu modelo enraizado no tradicional. Os registros, então, têm a capacidade de articular saberes de crianças e adultos envolvidos no processo de educar e cuidar, de modo a comunicar significativamente essas experiências, que quando representadas em imagens expostas, exalam o poder ético e estético dos agentes envolvidos na trama da Educação Infantil. 


\section{Considerações finais}

A escola, lugar em que os questionamentos, experiências e expressões deveriam estar em evidência, acaba contribuindo para a formação de imaginários e pontos de vistas moldados pelos meios de comunicação e pelos discursos adultocêntricos que, em grande parte das escolas que conhecemos, ainda permeiam o universo da Educação Infantil.

O trabalho com imagens nessa etapa da educação básica, quando bem pensado e planejado, pode ser uma maneira de oportunizar às crianças a ampliação de seus repertórios visuais, mas para que isso aconteça é importante que as e os professores também estejam dispostos a expandir seus repertórios imagéticos por meio de leituras, questionamentos e processos expressivos que abram espaços para novas experimentações e práticas educativas.

Como docentes, é importante nos apropriar das concepções de infância presentes nos documentos norteadores da Educação Infantil que acreditam na infância como um momento ativo e criativo da vida e, assim, criar possibilidades para romper com a ideia de que a infância é um período de fragilidade e inocência. Crianças são seres históricos e sociais que produzem e consomem cultura e a Educação Infantil precisa ser compreendida como um momento de se viver a infância, um momento em que as individualidades das crianças precisam ser respeitadas e suas potencialidades ampliadas.

Por tanto, ao pensar sobre utilização de imagens em práticas educativas na Educação Infantil, é importante questionar a escolha dessas imagens, pois elas têm força, potencialidades culturais e históricas que extrapolam a fisiologia dos olhos. É urgente que profissionais da Educação Infantil comecem a pensar nos modos de ver o mundo e de apresentá-lo às crianças de maneira mais significativa e plural, valorizando a expressão, a manifestação e problematizando nossas relações com as imagens que nos rodeiam.

O fato é que vivemos em uma sociedade em que, cada vez mais, o ato de ver imagens vai ser tornando uma ação banal, realizada de maneira automática, sem prestar atenção às narrativas e aos significados que elas carregam consigo e que delas emergem. Com o mesmo automatismo que recebemos as imagens, nós as perpetuamos e acabamos transmitindo uma autoridade sem nos dar conta do domínio e hegemonia expressados por elas. Por isso, é importante que professoras e professores da Educação Infantil estejam atentos, prontos a ouvir e a entender os interesses e necessidades das crianças, para que a partir dessa percepção sensível promovam atividades expressivas 
que desafiem o pensamento inventivo e sua capacidade de ver o mundo. As crianças têm muito a nos ensinar com seus movimentos e traços que percorrem o papel, às vezes de maneira despretensiosa, mas que deixam expressos ali seus saberes e suas subjetividades.

\section{Referências}

BRASIL. Ministério da Educação. Secretaria de Educação Básica. Diretrizes curriculares nacionais para a educação infantil. Secretaria de Educação Básica. Brasília: MEC, SEB, 2010.

CUNHA, S. R. V. Como vai a arte na educação infantil. In: Revista de Educação Presente. CEAP, Salvador: v. 56, p. 4-12, 2007.

DERDYK, E. Formas de pensar o desenho: desenvolvimento do grafismo infantil. 5 . Ed. - Porto Alegre, RS: Editora Zouk, 2015.

GOIÂNIA. Secretaria Municipal de Educação. Infâncias e Crianças em Cena: por uma Política de Educação Infantil para a Rede Municipal de Goiânia. Goiânia: SME, DEPE, DEI, 2014.

HERNÁNDEZ, F. Pesquisar com imagens, pesquisar sobre imagens: revelar aquilo que permanece invisível nas pedagogias da cultura. In: MARTINS, R.; TOURINHO, I. Processos \& Práticas de Pesquisa em Cultura Visual \& Educação. Santa Maria: UFSM, 2013.

MARTINS, A. F. Toda criança desenha... Toda criança desenha?! In: MARTINS, R.; TOURINHO, I. (Org.). Cultura Visual e Infância. Santa Maria: Editora UFSM, 2010.

MIRZOEFF, N. O direito a olhar. ETD - Educação Temática Digital, v. 18, n. 4, p. 745$768,2016$.

OSTETTO, L. E. No tecido da documentação, memória, identidade e beleza. In: OSTETTO, L. E. (Org.). Registros na educação infantil: Pesquisa e prática pedagógica. Campinas, SP: Editora Papirus, 2017.

ROSE, G. Visual Methodologies: An Introduction to the interpretation of visual materials. London: SAGE Publications, 2001.

SAMAIN, E. As imagens não são bolas de sinuca. Como pensam as imagens. In: SAMAIN, E. (Org.). Como pensam as imagens. São Paulo: Editora UNICAMP, 2014.

\footnotetext{
i Professora da Secretaria Municipal de Educação de Goiânia. Mestranda no Programa de Pós-graduação em Arte e Cultura Visual (PPGACV-UFG). Especialista em Educação Infantil, Alfabetização e Letramento pela Faculdade Brasileira de Educação e Cultura (FABEC). Graduada em Pedagogia pela Universidade Federal de Goiás (UFG).

ii Professora na Universidade Federal de Goiás (UFG). Atua no Programa de Pósgraduação em Arte e Cultura Visual (PPGACV-UFG) e nos cursos de Licenciatura em Artes
} 
Visuais e Bacharelado em Artes Visuais da Faculdade de Artes Visuais (FAV-UFG). Doutora em "Artes Visuales y Educación" (2014), pela Universidad de Barcelona (UB, Espanha), em regime de Cotutela com o Programa de Pós-graduação Arte e Cultura Visual da Universidade Federal de Goiás (UFG), Brasil.

Como citar esse artigo:

MOREIRA, Nara Mendes; ABREU, Carla Luzia. Pensando a educação infantil a partir de imagens. Revista Digital do LAV, Santa Maria: UFSM, v. 14, n. 1, p. 89-102, jan./abr. 2021. 